\title{
Metrics of Scrum Methodology
}

\author{
Ifra \\ Department of computer science \\ Punjabi university \\ Patiala
}

\author{
Jagpuneet Kaur Bajwa \\ Department of computer science \\ Punjabi university \\ Patiala
}

\begin{abstract}
While software metrics typically help to assess the status of a project, product and process the suitable metrics in Agile Software Development (ASD) process is frequently questioned due to overheads involved. The software provides processes for measuring and predicting the developed quantitative planning software. In this paper there are some metrics which could be beneficial to the ASD process.
\end{abstract}

\section{Keywords}

Agile Software Development, Software metrics, Scrum methodology, Scrum metrics.

\section{INTRODUCTION}

Software metrics are important in the software development life cycle. They give estimation to the product improvement, including the software needed reports, plans, projects and tests. Faster advancements of huge scaled, software have developed versatile nature that built the quality hard to control.

\subsection{Classification of Software Metrics}

There are three types of software metrics: [1]

\subsubsection{Process Metrics}

These metrics indicate promoting the process of software. It mainly focused on procedure team, incur costs and kind use approach. These metrics could be used to increase software promotion and support. An illustration incorporates the adequacy of imperfection eviction among progress, the response time of the fix procedure.

\subsubsection{Project Metrics}

These metrics are used to screen project conditions and status. These metrics include the issues or potential hazards by adapting the task and improve product promotion arrangement. Project metrics, enterprise the qualities and performance. An illustration incorporates the amount of software engineers, the staff designed the life cycle of the product, cost, schedule and efficiency. [2]

\subsubsection{Product Metrics}

These metrics are used to show the characteristics of the product item at any time of its promotion. Product metrics can measure the span of the project, complexity of product planning, implementation; wear ability, viability and item scale. These metrics used to accept and believe the nature of the item.

\section{METHOD}

\subsection{Research Questions}

This study has been undertaken as a literature review based on the guidelines as proposed by [1] [2] [6] [10] [12]. The steps in literature review method are documented below:

Q1. Which types of metrics are used in ASD process?

Q2. Which metrics are good for improvement of product quality?

With respect to Q1, we identified the number of metrics published per year, the journal/conferences that published them.

With respect to Q2, we considered the good metrics that improve the quality of the product.

\subsection{Search Process}

The selected journals and conferences are shown in Table1. The journals were selected because they were known to include the studies or surveys of the software metrics in agile testing.

Table 1. Selected journals and conference

\begin{tabular}{|l|l|}
\hline Source & Acronym \\
\hline International Journal of Advanced Computer Science and Applications & IJACSA \\
\hline International Journal of Recent Trends in Engineering & ACEEE \\
\hline Institution of Engineering and Technology & IETDL \\
\hline International Journal of Scientific and Engineering Research & IJSER \\
\hline IEEE Software & IEEE SW \\
\hline IEEE Computer Society & IEEE CPS \\
\hline Malaysian Software Engineering Conference & MySEC \\
\hline International Conference on Global Software Engineering Workshops & IEEE \\
\hline International Journal of Emerging Technology and Advanced Engineering & IJETAE \\
\hline Hawaii International Conference on System Sciences & HICSS \\
\hline Australian Conference on Software Engineering & ASWEC \\
\hline
\end{tabular}




\subsection{Data Collection}

The data extracted from each study were:

- The source (journal or conference) and full reference.

- $\quad$ Scope.
- Main topic area.

- Research question/issue.

- The author(s) and their institution and the country where it is situated.

- Summary of the study.

Table 2. Literature Review Studies

\begin{tabular}{|c|c|c|c|c|c|c|}
\hline Sr No. & Author & Date & Topic type & Topic area & $\begin{array}{l}\text { Article } \\
\text { type }\end{array}$ & Reference \\
\hline 1 & $\begin{array}{l}\text { Tu Honglei1, Sun Weiland } \\
\text { Zhang Yanan1 [1] }\end{array}$ & 2009 & $\begin{array}{l}\text { Software } \\
\text { Testing }\end{array}$ & $\begin{array}{l}\text { Software development } \\
\text { metrics }\end{array}$ & LR & IEEE paper \\
\hline 2 & $\begin{array}{l}\text { M. Kunz, Reiner R. Dumke } \\
\text { and Niko Zenker [22] }\end{array}$ & 2008 & $\begin{array}{l}\text { Software } \\
\text { Engineering }\end{array}$ & $\begin{array}{l}\text { Software development } \\
\text { metrics }\end{array}$ & SLR & IEEE paper \\
\hline 3 & $\begin{array}{l}\text { S. Downey and J. } \\
\text { Sutherland [3] }\end{array}$ & 2013 & $\begin{array}{l}\text { Software } \\
\text { Testing }\end{array}$ & Software metrics & SR & IEEE paper \\
\hline 4 & $\begin{array}{l}\text { K. V. J. Padmini, H.L.M. } \\
\text { Dilum Bandara and I. } \\
\text { Perera [21] }\end{array}$ & 2015 & $\begin{array}{l}\text { Software } \\
\text { Engineering }\end{array}$ & $\begin{array}{l}\text { Software development } \\
\text { metrics }\end{array}$ & SR & IEEE paper \\
\hline 5 & R. Akif and H. Majeed [20] & 2012 & $\begin{array}{l}\text { Software } \\
\text { Testing }\end{array}$ & Software metrics & LR & IJSER \\
\hline 6 & $\begin{array}{l}\text { Tulasi Anand and V.S. } \\
\text { Mani [19] }\end{array}$ & 2015 & Testing & Agile testing & LR & IEEE paper \\
\hline 7 & $\begin{array}{l}\text { M. S. Rawat, A.Mittal and } \\
\text { S. K. Dubey [4] }\end{array}$ & 2012 & $\begin{array}{l}\text { Software } \\
\text { Testing }\end{array}$ & Software metrics & SLR & IJACSA \\
\hline 8 & $\begin{array}{l}\text { T. D. Hellmann, A. Sharma, } \\
\text { J. Ferreira and F. Maurer } \\
{[17]}\end{array}$ & 2012 & Testing & Agile testing & SR & IEEE \\
\hline 9 & J.Miller[17] & 2010 & Testing & Acceptance testing & LR & IEEE \\
\hline 10 & $\begin{array}{l}\text { M. Suffian, S. Ibrahim and } \\
\text { M. R. Abdullah [16] }\end{array}$ & 2014 & Testing & Software testing & LR & IEEE \\
\hline 11 & $\begin{array}{l}\text { E. Collins, A. D. Neto and } \\
\text { V.F. de Lucena Jr. [18] }\end{array}$ & 2012 & Testing & Agile software testing & LR & IEEE \\
\hline
\end{tabular}

\section{DISCUSSION}

In Scrum, different metrics are used to follow the development of the project and working with team members. We identified 16 relevant metrics in the sources that we search are described below:

\subsection{Velocity}

This metric is used to complete the amount of the product backlog effort that put a team in tracing one Sprint. Members can rate measurement in terms of stories delivered by Sprint. This measure of productivity, team is used to compare working to the previous backlogs, which is used to estimate the contents of an exemption. [6]

\subsection{Standard violation}

This metric is used to violate the number of standards by Sprint track. The metric used to enforce coding standards. Using this metric force discipline in the team regarding code quality. Therefore, using this metric often to guide the team to right behavior during development.

\subsection{Business value delivered}

The company's value could be measured in terms of story points that how much value the company attached to a story. Team members can use the company's value to calculate the speed of the team and find the time to make a release. [6]

\subsection{Sprint goal success rates}

An effective sprint should have a working item that satisfies the sprint objectives and meets the scrum group's meaning of prepared: created, tried, coordinated and archived. [2] All through the undertaking, the scrum group can track how usually and again, it succeeds in achieving the sprint objectives and use achievement rates to see whether the group is developing the needs to accurate its course. [5]

\subsection{Defects per iteration}

This metric calculates the defects that occurred during a sprint. Because Sprint is a little expensive, defects are very expensive in Scrum and therefore should not calculate. [6]

\subsection{Total project duration}

Agile projects complete speedier than traditional projects. By beginning advancement sooner and removing bloat-ware pointless prerequisites agile undertaking groups can convey the item faster.

\subsection{Time to market}

Time to market is the measure of time an agile project takes to give esteem, either through inward usage or by creating wage, by discharging working items and elements to clients.

Time to market is particularly vital for organizations with income creating items, since it helps in planning consistently. It would be important if the user has a self funding project, i.e. paid by the product income. 


\subsection{Total product cost}

Duration relates to the cost on the agile as agile projects are quicker than traditional projects, they can likewise cost less. [5] An association can utilize project cost metrics to arrange spending plans, decide return in speculation and know when to practice capital redeployment.

\subsection{Return on investment}

Return on investment (return on initial capital investment) is wage created by the product, less project costs: cash in vs. cash out. On agile projects, return on initial capital investment is at a very basic level not quite the same as it is on conventional undertakings. Agile projects can possibly create wage with the main discharge and can build an income with each new discharge.

Return for money invested metrics are an awesome route for an association to value the continuous estimation of an agile project. Return for money invested metrics legitimize projects from the beginning, since organizations can finance projects taking into account return for money invested potential. Associations can track return of money invested for individual undertaking and additionally for the association all in all. [5]

\subsection{New requests within ROI budgets}

Agile project's capacity to rapidly create high return on initial capital investment gives association an extraordinary approach to finance extra product improvements. New item components may mean higher item wage. The organization can see high revenue on the projects that are providing some income.

\subsection{Determine Monitoring and Analysis Reporting}

Prioritizing the metrics also helps in setting how often to do reports for each of the metrics. [13] For example, high priority ones may be monitored weekly or every 15 days, while lower priority ones may be monitored monthly.

\subsection{Capital redeployment}

A scrum group's highest priority is to fulfill the client needs. In the meantime, the scrum group endeavors to inspire singular colleagues and advance supportable improvement rehearses. A scrum group can profit by digging more profound into client and colleague encounters through a survey of satisfaction. [5]

\subsection{Team member turnover}

Agile projects have a tendency to have high assurance. One method for evaluating confidence is by measuring turnover through several metrics:

\subsubsection{Scrum group turnover}

Low scrum group turnover could be one indication of a solid group environment. High scrum group turnover can demonstrate issues with the project, the association, the work, singular scrum colleagues, burnout, incapable product owners, compelling advancement group responsibilities, identity inconsistency, a scrum expert who neglects to expel obstacles or general group progression.

\subsubsection{Company turnover}

High organization turnover, regardless of the possibility that it does exclude the scrum group, can influence confidence and adequacy: high organization turnover could be an indication of issues inside the association. As an organization receives scrum practices, it might see a turnover reduction. [5]
At the point when the scrum group knows turnover metrics and comprehends the explanations for those metrics, it might have the capacity to take activities to resolve and enhance the workplace.

\subsection{Number of stories}

This metric calculates the number of stories in a release or a Sprint. [6]

\subsection{Number of tests}

This metric calculates the number of tests that have been developed, executed and passed to validate a story or the entire release. [6]

\subsection{Lack of cohesion in methods(LCOM)}

This indicates the number of states to be tested. LCOM indicates the number of methods that access one or more same attributes. [14] The value of LCOM is 0 , if no methods access the same attributes. As the value of LCOM increases, more states need to be tested.

\section{GOOD METRICS PROMOTE IMPROVEMENTS}

The formulas of good metrics are as follows: [3]

\subsection{Velocity}

Sum of the original estimates of all accepted work.

\subsection{Work Capacity}

The sum of all work reported during the Sprint, whether the SBI toward which the work was finished or not.

\subsection{Focus Factor \\ Velocity/Work Capacity}

\subsection{Percentage of Adopted Work}

Sum (Original Estimates of Adopted Work) / (Original Forecast for the Sprint)

\subsection{Percentage of Found Work}

Sum (Original Estimates of Found Work) / (Original Forecast for the Sprint)

\subsection{Accuracy of Estimation}

1 (Sum (Estimate Deltas) / Total Forecast)

\subsection{Accuracy of Forecast}

(Sum of Original Estimates) Sum (Sum of Original Estimates + Sum of Adopted Work + Sum of Found Work)

\subsection{Targeted Value Increase \\ Current Sprint's Velocity / Original Velocity}

\subsection{Success at Scale}

For each Point on the Fibonacci Scale $\left(F_{p}\right)$, the formula is:(Sum of No. Accepted Attempts of scale $F_{p}$ ) / (No. of All Attempts of scale $F_{p}$ )

\subsection{Win/Loss Record}

Each Sprint is a Win only if:

$$
\begin{aligned}
& \text { 4.10.1 A minimum of } 80 \% \text { of the Original } \\
& \text { Forecast is Accepted } \\
& \text { 4.10.2 Found + Adopted Work during the Sprint } \\
& \text { remains at } 20 \% \text { or less of the Original } \\
& \text { Forecast. }
\end{aligned}
$$




\section{CONCLUSION}

Software metrics are the basis of the software management and is essential for the achievement of development of software. It could be expected that by using software metrics will improve the overall rate of progress in software productivity and software quality. Accurate tracking helps the team to change its working practices to work and effective communication helps the pending tasks to ensure that the team work in the right direction.

\section{REFERENCES}

[1] Tu Honglei1, Sun Wei1, Zhang Yanan1, "The Research on Software Metrics and Software Complexity Metrics", International Forum on Computer ScienceTechnology and Applications, 2009.

[2] http://www.pearsonhighered.com/samplechapter/020172 9156.pdf.

[3] S. Downey and J. Sutherland, "Scrum Metrics for Hyperproductive Teams: How They Fly like Fighter Aircraft", in Proc. $46^{\text {th }}$ Hawaii International Conference on System Sciences, Hawaii, 2013, pp. 1530-1605.

[4] M. S. Rawat, A. Mittal and S. K. Dubey, "Survey on Impact of Software Metrics on Software Quality", International Journal of Advanced Computer Science and Applications, Vol. 3, No. 1, 2012.

[5] http://www.dummies.com/how-to/content/ten-keymetrics-for-agile-project-management.html.

[6] M. Agarwal and R. Majumdar, "Tracking Scrum Project Tools, Metrics and Myths About Agile", International Journal of Emerging Technology and Advanced Engineering, ISSN 2250-2459, Volume 2, Issue 3, March 2012.

[7] J. Sutherland, Scrum Handbook, Scrum Foundation, 2010.

[8] M. Beedle, M. Devos, Y. Sharon, K. Schwaber and J. Sutherland, "Scrum: A Pattern Language for Hyperproductive Software Development", in Pattern Languages of Program Design, vol. 4, N. Harrison, Ed., ed Boston: Addison-Wesley, 1999, pp. 637-651.

[9] www.agilescrum.com/.

[10] Extreme Chaos, The Standish Group International, 2001.
[11] K. Schwaber and M. Beedle, "Agile Software Development with Scrum”, Prentice Hall, 2002.

[12] http://agilealliance.com/articles/articles/InventingScrum. pdf.

[13] http://www.sourcingmag.com/agile-outsourcingmetrics-for-outsourced-software-development/.

[14] http://ecomputernotes.com/softwareengineering/classification-of-software-metrics.

[15] Hector M. Olague, Letha H. Etzkorn, Sampson Gholston and Stephen Quattlebaum, "Empirical Validation of Three Software Metrics Suites to Predict Fault-Proneness of Object-Oriented Classes Developed Using Highly Iterativr or Agile Software Development Processes", vol. 33, No. 6, June 2007.

[16] M. Suffian, S. Ibrahim and M. R. Abdullah, "A Proposal of Postgraduate Programme for Software Testing Specialization", $8^{\text {th }}$ Malaysian Software Engineering Conference, 2014, pp. 342-347.

[17] T. D. Hellmann, A. Sharma, J. Ferreira and F. Maurer, "Agile Testing: Past, Present and Future", Agile Conference, 2012, pp. 55-63.

[18] E. Collins, A. D-Neto and V. F. de Lucena Jr., "Strategies for Agile Software Testing Automation: An Industrial Experience", $36^{\text {th }}$ International Conference on Computer Software and Applications Workshops, 2012, pp. 440-445.

[19] Tulasi Anand and V. S. Mani, "Practices to make agile test teams effective: challenges and solutions", $10^{\text {th }}$ International Conference on Global Software Engineering Workshops, 2015.

[20] R. Akif and H. Majeed, "Issues and Challenges in Scrum Implementation", International Journal of Scientific \& Engineering Research, Vol. 3, issue 8, August-2012.

[21] K. V. J. Padmini, H. M. N. Dilum Bandara and I. Perera, "Use of Software Metrics in Agile Software Development Process”, pp. 312- 317, 2015.

[22] M. Kunz, R. R. Dumke and N. Zenker, "Software Metrics for Agile Software Development", $19^{\text {th }}$ Australian Conference on Software Engineering, pp. 673-678, 2008. 